\title{
Features of the design of social posters of the $X X I$ century and their role in the formation of ecological culture
}

\author{
Elena Vasilenko ${ }^{1}$, Pavel Vasilenko, ${ }^{1, *}$, Valentina Pallotta $^{2}$, Natalia Barsukova $^{3}$, and Tatyana \\ Sichkar ${ }^{4}$ \\ ${ }^{1}$ Federal State Budgetary Educational Institution of Higher Education " Moscow State University of \\ Technology and Management named after K. G. Razumovsky (First Cossack University)" \\ ${ }^{2}$ Moscow international University, Leningradsky prospect, 17, Moscow, Russian Federation \\ ${ }^{3}$ National Design Institute, Russian Federation, Moscow \\ ${ }^{4}$ Institute of World Civilisations, Moscow, Russia
}

\begin{abstract}
The article considers the poster design as a means of broadcasting and its role in the formation of ecological culture. The impact of the development of technological progress on the birth of completely new forms of the poster, which are not limited to one paper medium. The value of a social poster is in its content aspect, conceptual solution, wellchosen palette, composition. The language of graphic design changes along with the situation in society, becomes extremely figurative, exaggerated, metaphorical, symbolism takes the place of verbatim. The main task of the design of a social poster focused on nature conservation is to contribute to the formation of an ecological culture, starting with personal motivation for self-preservation and preservation of the environment, where the knowledge and skills of both each person individually and entire human communities. The purpose of the social poster is to orient the viewer to the commitment to the highest social values - such as humanism, love for people, for life, and nature. The poster is an iconic carrier of information, simple and understandable, which does not require intellectual efforts from the viewer and educates him both morally and aesthetically, influences a person's emotions, his attitude to the environment.
\end{abstract}

\section{Introduction}

Today, the topics of environmental responsibility and sustainable development of society are becoming more and more relevant at the state level around the world. Environmental pollution and eco-friendly business and lifestyle are increasingly relevant and urgent for humanity.

In the XXI century, some issues are most acute, and one of them is large - scale environmental problems that lead to serious crises in different parts of the world. The society faces the task of switching to a mode of conscious consumption, saving resources, caring for nature, and for this it is necessary to seriously transform our social and economic

\footnotetext{
* Corresponding author: pashavasilenko@mail.ru
} 
models of existence. Open to change, able to think critically and ready to act, activists of the environmental movement are already leaders in promoting the culture of careful and rational use of natural resources.

They introduce separate waste collection for further processing, organize environmental clubs and conduct eco-educational work, involve people of different ages and different social strata of society in public activities, learn to build a socially and environmentally responsible business taking into account the achievements of modern science. Greening can become and is becoming one of the indicators of effective life-activity of any society. The use of energy-efficient solutions, economical water supply, rational waste management in the future leads to cost reduction and careful attitude to natural resources. The activity in the implementation of "green" initiatives and projects gives significant advantages. One of the spheres in the formation of ecological culture is mass agitation, which depends on the visualization of socially significant concepts and images for society.

\section{Materials and methods}

Conducting a comparative analysis and comparison of the features of the design of a social poster, which is aimed at the formation of ecological culture, the trends in the change of poster art and their causes are noted.

Technological progress has contributed to the transformation of poster forms, which are not limited to one paper medium. The analysis of the appearance, creation and development of the poster design in the historical chronological sequence allows us to note its trend of change based on the trends and realities of the time. The latest trends in creating a graphic poster allow you to move from an abstract figurative image to a more concrete one. A comparison of visualization methods used in a social poster in different periods allows us to identify the stages of its development, which are characterized by the influence of political, ideological, cultural and other factors that characterize the era. When studying the current state in the field of graphic poster design, reconstruction of the past, namely the genesis-the emergence of stages of historical heritage, it is possible to identify a forecast of future trends for further development.

\section{Results and discussion}

The means for the formation of eco-culture are social videos, films, posters. The poster is the most concretizing, capacious, accessible and mass means of communication. The design of modern social posters plays an important role in the educational and cultural sphere of the environmental movement. Using all the possibilities of technological progress and a modern artistic language focused on the style preferences of the XXI century.

Currently, a poster means a type of large-format printed graphics that combines visual and font elements and performs an advertising, propaganda, educational or instructivemethodical function. His predecessors are considered to be propaganda engravings: for example, "flying leaflets" of the Reformation and peasant wars in Germany of the XVI century. The birth of the poster in its current form is associated with the invention of lithography in the late 1700s. The printing process in this way was quite long and expensive, but the artist Jules Cheret (1836-1932), considered one of the founders of the modern poster, after studying the English technology of color lithography, simplifies the technological process itself, which contributes to an increase in the size of circulations and the availability of production.

Throughout its history, the poster has been a reflection of reality, and its content and form have been determined by specific goals and dominant styles in art. So, the 
development of the poster fell on the modern era. The personalities who made the greatest contribution in this period are Jules Cheret, Henri de Toulouse-Lautrec, Alphonse Mucha. In Russia, these were artists who were part of the World of Arts association, especially Mikhail Vrubel. The poster of the Art Nouveau era was a full-fledged work of art made by masters of their craft, the main purpose of which was advertising [1]. Everything was advertised: from social events, exhibitions and entertainment venues to books, cigarettes and other products. This could be both the use of a pleasant image that catches the viewer's eye (most often - a female one, as in A. Mukha), and a verbatim image of the advertised object. The" fathers " of the advertising poster also outlined its main principles: catchiness (for which bright colors and accents were often used), conciseness, the ability to perceive information "on the go". At the same time, traditional pictorial and graphic means were used, which actually made a full-fledged illustration of the poster. Such posters had no purpose to morally educate society, it was only necessary to correctly submit the goods.

Since the beginning of the XX century, propaganda posters have become popular. The impetus for this was given by the First World War and the October Revolution that followed it, when political propaganda became the main task. The content is no longer a product, but an idea. The genre of the propaganda poster revealed itself most fully and vividly during the Great Patriotic War [2]. The elegance of modernity was replaced by loud slogans calling for a fight, a passionate image of the defender of the Motherland and the image of the enemy opposing him. The posters of this period were extremely straightforward and filled with emotions, their purpose is to raise morale and cause strong feelings. The first such poster was the famous poster of Irakli Toidze "The Motherland is calling!", released a few days after the start of the war and became a kind of personification of the unity of the country.

A social poster in the history of Soviet art calls for certain ideological things. This happened against the background of the domination of socialist realism, which sought to show the country rich, healthy, bursting with energy. The heroes of these posters are ideal citizens of their country, working people, happy families. Much attention was paid to the promotion of sports, a healthy lifestyle, ecology-the preservation of nature, motherhood, parasitism and drunkenness were strongly condemned [3, 4].

The Soviet environmental poster of the 1980s is not just beautiful pictures, they call for a conscious attitude to nature: "Stop, read, think, do what depends on you!". Posters of the 1980s are the heyday of social advertising of the Soviet state. There is no censorship, there are no strict and categorical artistic advice, there are no prohibited topics. An artist can create as he sees fit in order to reach the viewer, to convey what he wants to say. Social advertising calling for the protection of nature appeared in our country already in the sixties, although the topic of ecology was not as popular as a political poster, but it had its own established language, its own understandable images, traditional plots. Among the posters of the Soviet period concerning the topic of ecology, there are also unusual ones for example, the poster "Alcohol is a pain of nature" by Nikolai Ivanovich Litvinenko-a combination of two relevant topics at once: anti-alcohol propaganda in the framework of the 1985-1990 campaign and environmental protection, the work of Yakov Markovich Zlatopolsky "Less and less of the surrounding nature, more and more of the environment". Posters of graphic artist Mikhail Vsevolodovich Gromyko (in 1989, Uzbekistan) — " Is there a gift like spring water in the world? A drop is like a pearl, reflecting the heat of the sun." These paired posters tell the viewer about important things. We see how much depends on the skill of the artist who creates a bright and memorable image.

Vitaly Yevgenyevich Wolf, a well-known poster artist, spoke about the importance of poster art, that an image is important in a poster, the significance of a metaphor. A metaphor can only be expressed through an image. The main purpose of the poster is to stop the gaze of a random viewer, to interest, to capture his attention, to make him look, 
think, to cultivate certain positive qualities and attitudes in him. This fully applies to the environmental poster. But it is not enough just to catch and attract attention: it is important to show each person what he can do for himself and his children, his city, his country, his planet.

Technological progress has contributed to the birth of completely new forms of the poster, which are not limited to one paper medium [5]. But despite this, the value of the poster primarily lies in the content aspect, in the message and its readability, which work together with a well-chosen palette and composition. Using the rich experience of poster artists, contemporaries are guided by the global environmental problems of our time, trying to convey their thoughts in a new, understandable language. The role of social posters, namely posters that form the ecological culture of society, resonates in the modern world, where there is a global transition to a "green" economy. Reducing energy consumption, limiting the use of raw materials and water consumption, using highly efficient technologies, as well as reducing greenhouse gas emissions, preventing environmental pollution, reducing all types of waste in order to protect and restore ecosystems and biodiversity. To ensure the correct transition to a green economy, it is necessary to educate a certain eco-culture, to train not only influential politicians, but also all segments of the population.

The formation of "green" skills, ecological culture depends on the desire to learn throughout life, personal motivation for self-preservation and preservation of the environment. The knowledge and skills of both each individual and entire human communities, their commitment to the highest social values - such as humanism, love for people, life, and nature - will help preserve the ecology of the planet. To do this, it is necessary, first of all, to change the public consciousness of people. It is the consciousness of people that should be ready for changes. It will not be enough to train only the younger generation or only employees of a certain sphere, it is necessary to educate and teach "green" skills to all citizens [6. 7].

Since the birth of the poster and until the middle of the XX century, with all its variety of subjects and messages, it remained uncomplicated, straightforward, clearly expressing a certain idea through clearly readable pictorial images. At the moment, we can say that the traditional look of the poster has undergone a significant transformation [8]. The reason for this is a variety of factors. From the technical side, this is a large selection of tools without any restrictions: from traditional materials and mixed techniques to photographs, collaging, the use of computer and electronic technologies. Another significant reason is the change in values and the allocation of the most acute social problems of the XXI century, which previously receded into the background. The graphic language changes along with the situation in society, becomes extremely figurative, exaggerated, metaphorical, symbolism takes the place of verbatim. If earlier the aesthetic (setting the choice of materials and artistic techniques) and social (dictating the semantic content) components in the poster were balanced, now more and more often the main emphasis is placed on the latter, and questions of aesthetics either obey it or are discarded altogether $[9,10]$. This is due, firstly, to a change in the attitude to art as such. Modern art has long not gravitated towards the sublime, since it is no longer focused on the same creator, but on a simple person, "communication" with whom is sometimes reduced to primitive things and simplified silhouettes. This applies most closely to the design of the poster, since it is the kind of art that a person regularly encounters in everyday life and his task is to be understandable. Secondly, the reason lies in the very appearance of the urban environment [11]. 

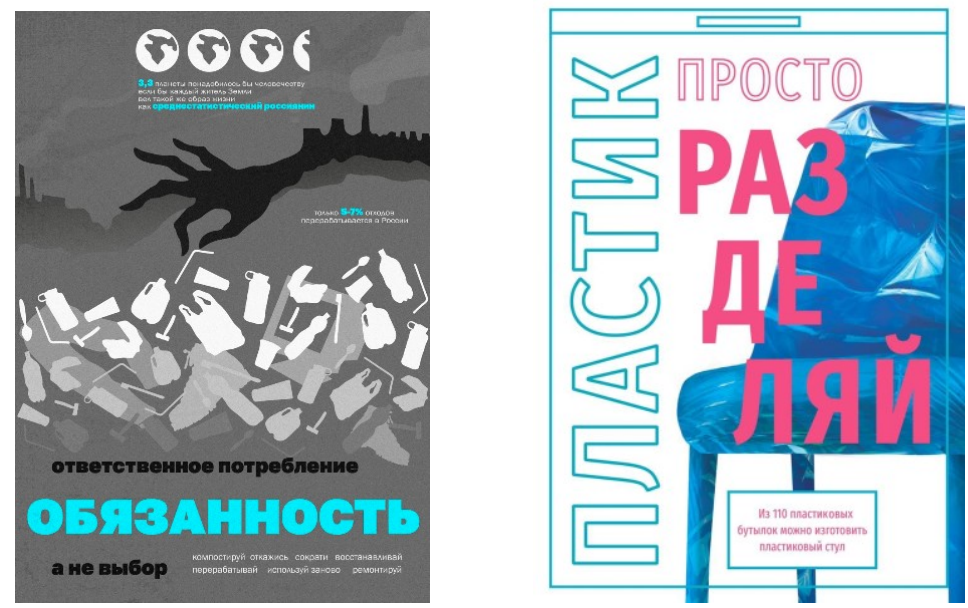

Fig. 1. Posters of students of the Moscow State Technical University named after K. G. Razumovsky (Anastasia Glukhova, Daria Chuvilina).

\section{Conclusion}

The poster has always been and remains the most common way to convey information by minimal means. However, with the development of industrial society and mass communication media, the city turned out to be oversaturated with information: the streets were filled with bright signs, advertising billboards and banners, posters. Given the dynamic rhythm of urban life, it has become more difficult for a traditional poster to attract the attention of a passing viewer, and therefore most modern posters are simple forms (and sometimes even their absence with an emphasis on text), made in a flashy limited palette. Here there is a fine line between a symbol that is understandable to everyone, and the complete erasure of the image, its abstractness and ambiguity for the sake of visibility. If the recipient who receives such a message now needs to think about its message, despite the simplicity of the forms and a cursory glance is not enough, the question arises about the effectiveness of this form of dialogue. Here, the problem of copying and self-copying arises: the simpler forms are used, and the design becomes typical, the more difficult it is to visualize information so that it attracts attention and at the same time causes the necessary response from others [12]. The poster as an iconic carrier of socially significant information should not give way to tasteless advertising, which does not require any intellectual effort from the viewer and does not educate him both morally and aesthetically. Art must have a direct impact on a person's emotions [13, 14].

To preserve life on our planet, it is necessary, first of all, to change the public consciousness of people. It is the consciousness of people that should be ready for changes.

The role of the modern social poster is undeniable, its task is to participate in the process of educating and teaching the ecological culture of society in all segments of the world's population, of all ages, using visualization tools.

\section{References}

1. S. N. Begidova, P. G. Vasilenko, Bulletin of the Adyghe State University. Series 3: Pedagogy and Psycholog, 3 (2016)

2. L. K. Vartanova, The space of dialogues: fine art and design (2017) 
3. A. M. Glukhova, T. E. Belyakova, Science: the view of the young. Collection of materials of the scientific conference (2020)

4. E. V. Demkina, E. V. Lopasova, Formation of compositional thinking among students of fine arts in the system of additional education: state, problems and prospects (2016)

5. M. V. Domasev, Color, color management, color calculations and measurements (2009)

6. A. V. Kotyshov, Education. The science. Culture. GSU, Electrical Insulator (2015)

7. M. A. Smirnova Pedagogical education at the junction of epochs: innovations and traditions in the field of educational technologies (2017)

8. E. V. Vasilenko, Modern science, 9-1 (2019)

9. I. V. Alekseeva, N. I. Barsukova, V. I. Pallotta, N. A. Skovorodnikova, European Journal of Modern Education, 6 (2017)

10. M. A. Smirnova, E. V. Vasilenko, International Scientific and Practical Conference "Actual Problems of Linguistics and Didactics: an interdisciplinary approach in the Humanities and Social Sciences" (CILDIAH-2019), (2019)

11. G. G. Sunaeva, S. G. Sunaeva, T. E. Belyakova, K. N. Chevalier, SHS Web of Conferences. International scientific and practical conference "Theory and practice of project management in education: horizons and risks" (2020)

12. E. V. Fomina, N.I. Barsukova, Intercession, 44, 4 (2019)

13. E. Yu. Ivanova, T. E. Belyakova, L. V. Novikova, V. V. Koreshkov, Espacios, 40, 17 (2019)

14. T. Pushkareva, D. Agaltsova, E. Ivanova, T. Belyakova, Economic and social development (2018) 